Conference Article

\title{
Microstructure and Properties of an AA2139 Alloy Welded Joint Produced by Linear Friction Welding
}

\section{Kiseleva S.K., Medvedev A.Y., Bychkov V.M., Bolshakov B.O., Alexandrov I.V. and Musin F.F.}

Ufa State Aviation Technical University, Ufa, Russian Federation

Received 1 September 2015; Accepted 8 September 2015

\begin{abstract}
Microstructure and mechanical properties of a solid-phase joint produced by linear friction welding of AA2139 alloy samples have been studied. It has been shown that the weld formed as a result of LFW of two rectangular-shaped samples does not have macroscopic defects and has a high strength. It has been that the microstructure transforms significantly in the weld line during plastic deformation and deformation heating.
\end{abstract}

Keywords: aluminum alloy, linear friction welding, microstructure, mechanical properties.

\section{Introduction}

Today linear friction welding (LFW) is a key technology to form weld joints in aeroengine manufacturing [1]. This technology is more economical to produce bladed integrated disk assemblies in joining fan and turbine blades to disks instead of their manufacture from solid semi-items. The main advantages of this welding technology are minimal volume of heated material affected and the quick processing times. The LFW technology has been most successfully applied to heat resistant Ti alloys and steels [2-6] and can be applied to produce joints from dissimilar materials [7].

LFW applied to Al alloys is also interesting from the point of view of its use in producing a fan stage of a gasturbine engine. There has been experience in producing LFW joints with Al alloys. Thus, the possibility of a defectfree weld joint production from D16 alloy of the Al-Cu-Mg system with LFW technique is described in $[8,9]$. As there has been major progress in using Al alloys to produce firststage blisks with Al alloys containing Ag, and AA2139 is an example of such alloy. This alloy possesses high values of crack and heat resistance. A large number of intermetallic phases in the structure can pose restrictions and problems when producing such a high-quality weld joint.

Thus, the aim of this work is to study the microstructure and mechanical properties of Al alloy AA2139 produced by LFW.

\section{Experimental}

The Al alloy AA2139 (Al-4.3Cu-0.485Mg-0.35Mn-0.53 Ag) was chosen for studies. The An initial semi-product was a hot-rolled rod produced with semicontinuous casting.

The MDS LFW machine was used for welding samples. The system of the unit hydraulic drive control ensures

* E-mail address: nurieva_s@mail.ru ISSN: 1791-2377 (c) 2015 Kavala Institute of Technology. All rights reserved. maintenance of vibrational motion with the set frequency and amplitude and a possibility for post-weld upsetting. The process duration was set indirectly, where the reciprocating motion of parts was arrested upon achievement of the set upsetting value - or "heating upsetting" in the terminology of the machine.

Samples in the shape of parallelepipeds with a cross section of $13 \times 26 \mathrm{~mm}$ and length of $40 \mathrm{~mm}$ were cut out along the rod length direction. The main welding parameters were chosen based on the MDS specifications.

The microstructure was studied with the help of the optical microscope "Olympus GX51". A thin structure was analyzed with the transmission electron microscope (TEM) "JEOL JEM-2100".

Microhardness was measured on a hardness gauge instrument "Struers Duramin-2" at an applied load of $1 \mathrm{~N}$ for 10 seconds along the line perpendicular to the weld joint line.

Static tensile tests were performed at room temperature on 2-mm thick flat samples with the help of a universal testing machine "Instron 5982".

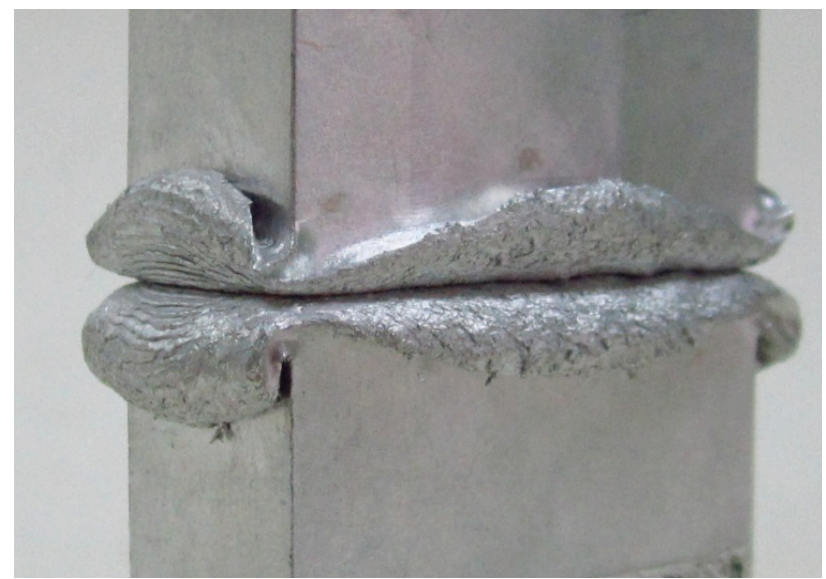

Fig 1. View of the sample after LFW 


\section{Results}

The image of the sample after welding is displayed in Fig. 1. A massive flash forms on the sample. Cracks are not observed to form on the flash.

After the flash was removed, no visible defects like discontinuities, no fusion areas and pores were observed in | the weld line zone (Fig. 2). The weld line of two samples resembles a concave lense expanding towards opposite ends.

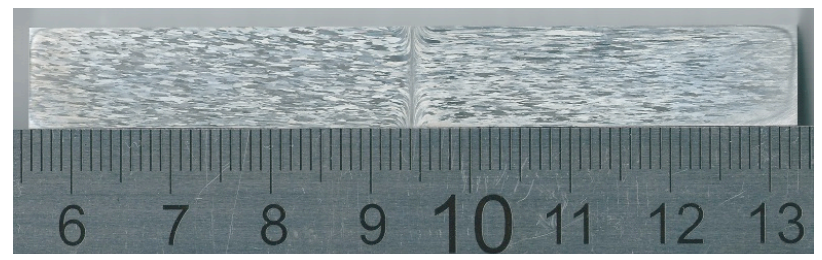

Fig. 2. Macrostructure of AA2139 alloy after LFW

As a result of LFW the alloy microstructure in the weld line area and near the line zone changes significantly (Fig. 2,3). One can observe several zones which differ in grain shape and size.

A zone of base metal (BM) is characterized by a welldefined metallographic texture formed during semi-product manufacturing (Fig. 3a). Initial matrix grains are elongated in the rolling direction, which precedes linear friction welding. The average grain length is $1500 \pm 100 \mu \mathrm{m}$, the average thickness is $300 \pm 50 \mu \mathrm{m}$. The average grain shape coefficient is $50 \pm 12$. The elongated grains are directed perpendicularly to the seam line.

In the thermo-mechanically affected zone (TMAZ) grains are oriented towards high-temperature plastic flow during LFW (Fig. 3b). However, the zone length is insignificant and makes $2.0 \pm 0.5 \mathrm{~mm}$. As a comparison this value for welded samples of D16T was 4-5 mm [5, 8]. Besides these, equiaxed grains are not observed in the structure of this zone, which were found in D16T [5, 8].

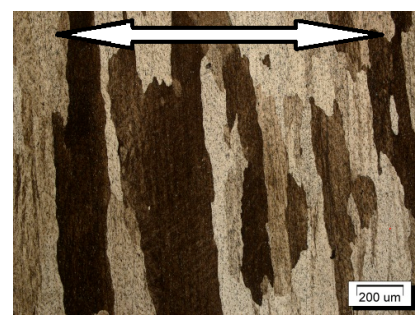

a)

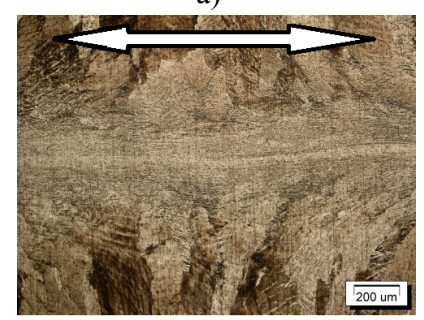

c)

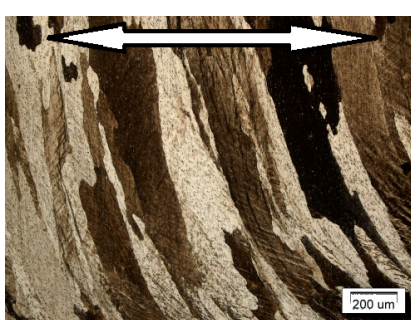

b)

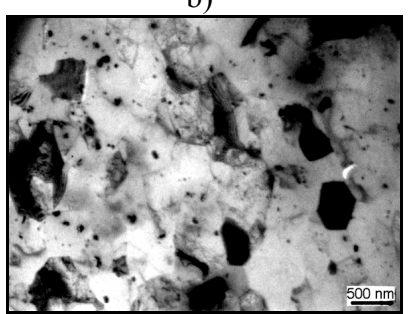

d)
Fig. 3. Microstructure of AA2139 alloy after LFW a) BM; b) TMAZ; c) weld centre. The arrow indicates the plane of welding.

The weld centre differs essentially in the ability to be etched from the rest zones (Fig. 3c). It is impossible to define grain boundaries by etching in this zone, which could testify to a high level of work hardening during plastic deformation and small sizes of structural elements. The microstructure analysis with the help of TEM shows equiaxed grains in the weld line zone. The average grain size is $0.6 \pm 0.1 \mu \mathrm{m}$ (Fig. 3d). Appearance of equiaxed grains is connected with dynamic metadynamic recrystallization processes.

The Al alloy AA2139 is known to have a very complex alloying. Different phases can be found in it depending on treatment. The phases are $\Omega, \theta^{\prime \prime}, \theta^{\prime}(\mathrm{Al} 2 \mathrm{Cu}), \mathrm{S}^{\prime}\left(\mathrm{Al}_{2} \mathrm{CuMg}\right)$ and $\mathrm{T}\left(\mathrm{Al}_{6} \mathrm{CuAgMg}\right)_{4}[10,11]$. During LFW metal heating combined with plastic deformation can lead to change in the phase composition at the expense of dissolution or precipitation of different phases. In its turn this can be accompanied by microhardness changes close to the weld line.

The microhardness after LFW was measured across the weld line. Fig. 4 shows that the microhardness reduces by $30 \mathrm{HV}$ on the average during transition to the thermomechanically affected zone and weld centre zone.

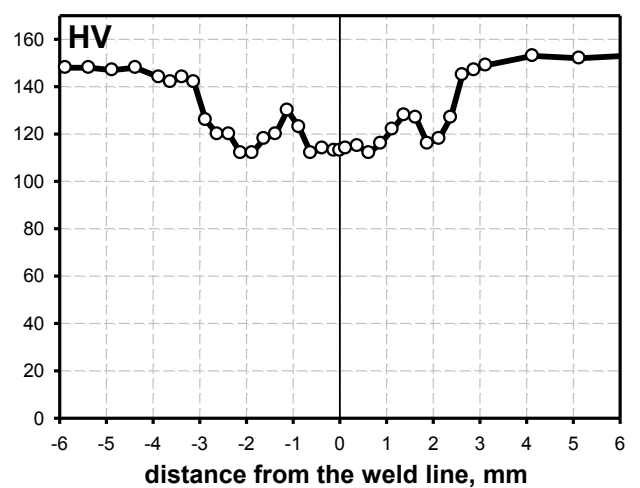

Fig. 4. Microhardness distribution in the sample after LFW

The static tensile test results demonstrate that the weld joints possess high strength properties. The maximum strength of samples is $\sigma_{\mathrm{U}}=390 \mathrm{MPa}$, the minimal one is $382 \mathrm{MPa}$.

Table 1. Mechanical test results

\begin{tabular}{c|c|c}
\hline Sample No & $\boldsymbol{\sigma}_{\mathbf{U}}, \mathbf{M P a}$ & $\boldsymbol{\sigma}_{\mathbf{0 . 2}}, \mathbf{M P a}$ \\
\hline 1 & 389 & 294 \\
2 & 382 & 295 \\
3 & 387 & 293 \\
4 & 390 & 295 \\
\hline
\end{tabular}

The sample view after testing is displayed in Fig. 5.

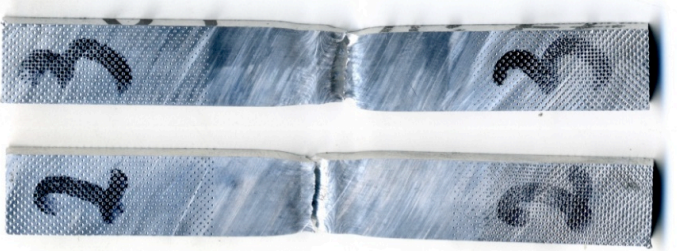

Fig 5. View of samples after tension

Two necks form due to high heterogeneity of the structure inherent to the material after LFW. The necks are situated symmetrically at a distance of $2-3 \mathrm{~mm}$ from the weld centre. 
Kiseleva S.K., Medvedev A.Y., Bychkov V.M., Bolshakov B.O., Alexandrov I.V. and Musin F.F.

Journal of Engineering Science and Technology Review 8 (6) (2015) 30 -32

\section{Conclusions}

The performed studies demonstrate that linear friction welding of Al alloy AA2139 has resulted in fabrication of a defect-free weld joint.

It has been stated that the microstructure changes significantly in the weld seam zone during plastic deformation and deformation heating. During thermomechanical impact recrystallization processes take place in the alloy, which lead to formation of a recrystallized structure with an average size of $0.6 \pm 0.1 \mu \mathrm{m}$ in the seam zone.

\section{Acknowledgments}

This work was performed with financial support from The Ministry of Education and Science of the Russian Federation within the framework of the design part of the state task №11.2540.2014/K educational organization of higher education

\section{References}

[1] Bhamji I., Preuss M., Threadgill P. L., Addison A. C., "Solid state joining of metals by linear friction welding: a literature review", Materials Science and Technology, vol. 27, No. 1, p.3-12, 2011.

[2] W.-Y. Li, T.J. Ma, S.Q. Yang, Q.Z. Xu, Y. Zhang, J.L. Li, H.L. Liao "Effect of friction time on flash shape and axial shortening of linear friction welded 45 steel" Materials Letters, vol.62, p.293-296, 2008.

[3] Zakirova A. A., Nagimov M. I., Khusnullin A. M., Kashaev R. M., "Structure, properties and hot deformation of a welded joint of steel 08KH18N10T, obtained by linear friction welding (LST)", Advanced materials, p. 155-159, 2011. (in Russian).

[4]. Karadge M., Preuss M., Lovell C., Withers P.J., Bray S. "Texture development in Ti-6Al-4V linear friction welds”, Materials Science and Engineering A, vol.459, p.182-191, 2007.

[5]. Karavaeva M. V., Kiseleva S. K., Bychkov V., Medvedev, A. Y., Soups, A. V., Musin, F. F., Alexandrov I. V., Latysh V. V., "Influence of the magnitude of precipitation on the formation of the welded joint during the linear friction welding", Letters on materials vol.2, p.40-44, 2012. [in Russian]

[6]. Romero J., Attallah M.M., Preuss M., Karadge M., Bray S.E, "Effect of the forging pressure on the microstructure and residual stress development in Ti-6Al-4V linear friction welds", Acta Materialia vol.57, p.5582-5592, 2009.

[7]. Bhamji I., Moat R. J., Preuss M., Threadgill P. L., Addison A. C., Peel M. J. "Linear friction welding of aluminum to copper", Science and Technology of Welding and Joining, vol. 7, no.4. p.314-320, 2012.

[8]. Kiselyeva S.K., Astanin V.V., Gareeva L., Bychkov V.M., Medvedev A.Y., Musin F.F., Alexandrov I.V., "Microstructure and Mechanical Properties of Joint Welds Formed by Linear Friction Welding in Al-Cu-Mg Alloy", Journal of Engineering Science and Technology Review, vol.7, Issue 5, p. 32-35, 2014.

[9]. Medvedev A., Vairis A., Nikiforov R., Supov A., "Energy Balance of the Linear Friction Welding Process", Journal of Engineering Science and Technology Review, vol.5, Issue 3, p. 20-24, 2012.

[10]. Ber L.B., Teleshov V.V., Ukolova O.G. "Phase composition and mechanical properties of wrought aluminum alloys of the system Al$\mathrm{Cu}-\mathrm{Mg}-\mathrm{Ag}-\mathrm{Xi}$ ", Materials science and heat treatment of metals, no.5. p. 15-22, 2008. [in Russian]

[11]. Gemchugnikova D.A., Gazizov M.R., Tagirov D.V. "Influence of annealing on structure and mechanical properties of the alloy system Al-Cu-Mg-Ag”, Technology of light alloys, 2013. [in Russian] 